tinent so well revealed in north-western Europe. The main folding, however, in Bohemia and Moravia, accompanied by great intrusions of granite and the formation of large areas of gneiss, occurred in connection with the "Variscan" movements-that is, in Upper Devonian and Lower Carboniferous timesthus heralding, and still at a long distance, the Armorican movements of the west. This fact is emphasised by Radim Kettner, writing from Pr bram (1917, p. 251).

In the same year (p. 267) J. Woldrich examined the Cretaceous fauna of Neratovic, where concretions containing 50 per cent. of calcium phosphate interestingly occur. This discovery is compared with the presence of phosphatic nodules in the Cretaceous of France and England, and (p. 32I) the fauna is described in relation to its western representatives. In the volume for I9I5 (p. I) C. Zahálka contributes a far-reaching memoir on the Cretaceous system in the Sudetic region and its equivalents in the western lands of Central Europe. This includes many pleasant references to the comradeship shown to the author by French geologists, and the name of Valmy, where the First Republic answered the proclamation of the coalised kings, appears here happily (p. rog) in connection with field-work on the zone of Inoceramus labiatus. There is much in this extensive paper to interest English geologists, who must, by the way, not overlook Richard J. Schubert's paper (I9I5, D. 277) on otoliths of Barton Cliff in Hampshire, collected by H. Elliot Watson and sent to the author by Col. C. D. Shepherd. Schubert's death at the head of his company in the heroic fight at Gorlice on the Russian front (obituary by O. Ampferer, I9r5, p. 26I), removed a very active and much-loved personality from the ranks of the Reichsanstalt.

British and Indian geologists may also note Rudolf Zuber's contributions to the geology of the Punjab (I9I4, p. 327), resulting from explorations organised bv an English oil company in ror 3 . There are two highlv suggestive diagrams showing the interlocking of different types of Eocene strata, including the salt- clay series, and their folding in the great Himalayan movements to form the present Salt Range.

Broad questions of petrography have not escaped the attention of the Reichsanstalt, such as Bruno Sander's “Beiträge aus den Zentralalpen zur Deutung der Gesteinsgefüge" (19I4, p. 567), in which the stratified and folded structures in many crystalline rocks are recognised as of earlier date than the crystal. lisation of their present mineral constituents; or the extensive study of peridotites and their allies involved in F. Kretchmer's memoir on "Der metamorphe Dioritgabbrogang im Spieglitzer Gebirge" (I9I7, p. I). Palæontology is represented by ${ }_{r}$ a number of short papers, including one by J. V. Zelizko (I9I8, p. II 3 ) on a small species of lion from the Pleistocene of Wolin, in southern Bohemia. One large folio memoir, on Oxynoticeras, by $\mathrm{J}$. von $\mathrm{Pia}$, was issued in $19 \mathrm{I} 4$; it includes the usual considerations in regard to what constitutes a genus or a species, to which we are accustomed when ammonites are brought into the arena. In critical biography E. Tietze's "Einige Seiten über Eduard Suess" (I9r6, p. 333), a paper of more than 200 pages, is a very memorable review of the recent history of geology. Even the papers on economic subjects reflect the calm detachment of the institute, encouraged to carry on its work with a cosmopolitan outlook, during a catastrophe that has broken the bonds of man to man by more than inexorable death. Even F. von Kerner's study (ror6, p. 145) of the water-supply in the Middle Dalmatian karst-region, with its valuable series of sections, will be to the advantage of the Slavonic peoples rather than to those who blasted their trenches on the Carso in the hope of retaining a sovereignty at Trieste. And so, indeed, it should be alwavs. The Austro-Hungarian Festland has become broken into horsts and Graben; but will not time smooth the fault-scarps that now loom un as separating walls? The best guarantee of scientific co-operation is to be seen in the names of those who have. during vears of bitterness and division, contributed in serene hopefulness to the sum of human knowledge.

\title{
Measurements of the Angular Diameters of Stars.
}

FTER the successful measurement of Capella as A a double star by Prof. A. Michelson's interferometer method applied to the roo-in. reflector at Mount Wilson, it was known that he intended to attempt the more difficult feat of measuring stellar diameters. The most hopeful stars to choose for the purpose are the giant red stars. Prof. Eddington made some estimates of their angular diameters in his inaugural address to Section A of the British Association last August (Nature, September 2, I920, p. 14). Taking the temperature and surface brightness derived from the distribution of energy in the spectrum, the angular diameter (which is independent of the assumed distance) is deducible from the apparent magnitude. The highest estimate for any star was that for Betelgeux, the value being $0.05 \mathrm{I}^{\prime \prime}$.

The daily Press of December 3I announced that Prof. Michelson read a paper before the American Physical Society in which he stated that he had determined that the diameter of Betelgeux was $260,000,000$ miles, or three hundred times that of the sun. As the assumed distance of the star was given as $x_{50}$ light-years, we may infer that the measured angular diameter was $0.06 \mathrm{I}^{\prime \prime}-\mathrm{a}$ close agreement with Prof. Eddington's estimate. ${ }^{1}$ Once the angular dia-

1 A later communication gives $0^{\circ} 046^{\prime \prime}$ as the measured diameter. NO. 2673 , VOL. IO6] meter of a single $\mathrm{Ma}$ star is determined, those of all the stars of the same spectral type can be deduced from their apparent magnitudes. The huge bulk of Betelgeux is a striking illustration of Prof. H. N. Russell's theory of giant and dwarf stars. Its density is presumably very low, otherwise an improbably high value of the mass would result.

Some further details of the result obtained at Mount Wilson were communicated in a letter from Prof G. E. Hale which was read at the meeting of the Royal Astronomical Society on January i4. The apparatus consists of two periscopes fixed to a frame at the object-end of the tube of the roo-in. Hooker reflector. The outer mirrors are some $20 \mathrm{ft}$. apart, but the distance is capable of being varied. The inner mirrors are about $4 \mathrm{ft}$. apart; this is merely a matter of convenience, the beams being brought down the tube on opposite sides of the Cassegrain mirror. An additional plane mirror is used for reflecting the light up the polar axis. The measurement of a star's diameter is effected by varying the distance between the outer mirrors and finding the points at which the interference fringes disappear. The actual observation is very tedious and difficult; it was stated that half an hour was required each time the mirror was moved before the visibility of the fringes could be tested. Moreover, in measuring a star disc, observations are 
required in different azimuths to ascertain that we are dealing with a single circular disc, and not with two neighbouring discs, as in the case of Capella. The resulting angular diameter is $0.045^{\prime \prime}$; Prof. Eddington had predicted $0.05 \mathrm{I}^{\prime \prime}$ from the visual magnitude and assumed surface brightness, and Prof. Seeliger deduced $0.042^{\prime \prime}$ in a somewhat similar manner. The linear diameter found (about 300 times that of the sun) depends on the assumed parallax, which, unfortunately, is decidedly uncertain; further determinations seem urgently to be called for. Prof. Lindemann pointed out the extraordinarily low density that such a diameter implies if we assume that the mass is of the order of twenty-five times that of the sun.

Other stars for which a diameter determination is hopeful are Antares and Aldebaran, and possibly Arcturus. Sirius and Vega will doubtless be attempted, but with less prospect of success.

A. C. D. C.

\section{Culture and Environment in the Cameroons.}

$\mathrm{FEW}$ areas in the African continent present problems of greater interest to the anthropologist than the Cameroons. Although the Germans produced a considerable amount of literature relating to the area while it was under their rule, there is still a great deal of work to be done before the complex ethnology of the country is elucidated. Capt. L. W. G. Malcolm, who saw service in the Cameroons during the war, is preparing a monograph which will be one of the first-fruits of our occupation. At a recent meeting of the Royal Anthropological Institute he gave a preliminary account of certain questions connected with the distribution of types of culture and its relation with the geographical environment.

In the Cameroons there are three main racial stocks, namely, the Bantu-speaking tribes, the Sudanese, and the Pygmies. Subsidiary immigrant races occupy certain areas in the north-east. Between the Bantu-speaking tribes and the Sudanese there are a number of tribes, some of which do not speak Bantu languages, and there is a distinct boundary between the Bantu-speaking and Sudanese races which is determined solely by the geographical nature of the country.

The material culture of the grassland area reveals the fact that the problem is of a most complex character. When dealing with tribes of mixed affinities it is extremely difficult to determine the various strata. Not only is there a local mixing of the tribes, but there are also various elements which have been brought in by invading tribes. This is partisularly the case in Bagam, where the tribe has been in- fluenced particularly from Bamum, in the north-east, while from Babanki, in the north, various forms of iron weapons have been introduced. The Balis have introduced among the grassland tribes the sleeveless gowns worn by the men. After Hausa and Fulani elements and the influence of the forest-beit tribes have been eliminated, it would appear that the chief characteristics of the grassland culture are weapons of copper, iron, and brass; socketed spearheads; a simple bow made from raphia palm, with a flat bowstring; arrows with wooden points; shields, either plaited or reinforced with wood; wooden slit-gongs; drums with skin tympana and wooden tautening wedges; flanged iron bells; iron-working (smelting and smithing); brass castings (Bagam and Bamum); pottery (coiled in the north-east); jutan cloth and woven fibre; decorative art with triangles and zigzags; cicatrisation; filing or chipping of the incisors; smoking pipes of metal and clay; animal and ancestral cults; and the use of carved masks and images. One of the most obvious and striking peculiarities of the grassland culture, however, is the quadrangular hut, with pyramidal or conical roof, ranged in streets, which differs distinctively from the forest-belt hut standing in its own irregularly placed clearing.

Capt. Malcolm's careful analysis of the culture of one area only of the Cameroons, even in this preliminary form, was not merely an indication of the extremely interesting material which still awaits investigation; it was also a valuable object-lesson of the method of studying a backward population which should form the essential basis of our administration in this and similar areas.

\section{The Science Masters' Association.}

$A^{T}$ the invitation of the Board of the Faculty of Natural Science, the annual meeting of the Science Masters' Association was held in Oxford on January $4-7$. About two hundred members attended, and by the kindness of the Master of Balliol and the President of Trinity they were housed in these two colleges.

The meeting began on the evening of January 4 with the address of the president (Mr. A. Vassall, of Harrow) on "Some Aspects of Science and Education." Mr. Vassall dealt with education in science from the preparatory school to the university, and showed the evils of teaching in the earlier stages as if all the boys were ultimately to become specialists. The teaching should be such as to give every boy an opportunity of realising the scope and aims of science. It should impart to every boy the understanding of scientific problems necessary for the equipment of a modern State, and not be merely a training for future work in science, which in many cases will never be taken up seriously.

A lecture on spectroscopy, given by Prof. T. R. No. 2673 , VOL. IO6]
Merton, was concerned largely with the part played by observation and technique; observation cannot be effective with faulty apparatus. In the spectroscopy of gases the influence of traces of impurities is very great, and many beautiful experiments were shown to illustrate the methods of dealing with them. The conditions under which nitrogen gives a band spectrum and a line spectrum were shown; a tube was exhausted and filled with helium sufficiently free to enable the conditions for obtaining either a band spectrum or a line spectrum to be demonstrated. Also, a striking experiment was shown by which the presence of neon in the atmosphere was made evident. The method of getting hydrogen into and out of tubes by means of a heated side-tube of palladium was illustrated, and the curious fluorescence of parts of the human body was shown by illuminating the audience by light of wave-length about $3660 \AA$.U., obtained by using a quartz mercury vapour lamp and a screen of special glass devised by Prof. R. W. Wood.

There were demonstrations in the various University laboratories, illustrating much of the teaching 